\title{
Correlation of Body Mass Index (BMI) with age of Menarche in Adolescent Girls
}

\author{
D. Sudha ${ }^{1}$, Sonipriya Somu ${ }^{2}$, Leya Elizabeth Babu ${ }^{3}$, N. Kannan ${ }^{4}$ \\ ${ }^{1}$ Associate Professor, ${ }^{2}$ Third year student, ${ }^{3}$ Assistant Professor, ${ }^{4}$ Professor \& Head of the Department, Department \\ of Physiology, Melmaruvathur Adhiparasakthi Institute of Medical Sciences and Research, Melmaruvathur
}

\begin{abstract}
Background: Occurrence of menarche at the earlier age has been attributed to a significant number of adverse health outcomes. Depression, eating disorders, metabolic syndrome and Type II diabetes mellitus have been identified as the major adverse health related issues. Furthermore in relation to early age of menarche has been identified as a risk factor for breast and endometrial cancer due to the increased exposure to estrogen. Hence, it is important to give awareness in adopting healthy eating habits and involving in daily physical exercise.
\end{abstract}

Aim: To measure the body mass index in adolescent girls and correlate between the age of menarche and body mass index in adolescent girls.

Methodology: This is cross-sectional study with a sample size of 200 female students between the age group of 17 - 19 years attending different courses (MBBS, BDS, AHS and BPT) in Melmaruvathur Adhiparasakthi Institute of Medical Sciences and Research, Melmaruvathur. An informed consent will be obtained from the participants. A dietary history will be taken by questionnaire. The anthropometric measurements for calculating the BMI will be measured using calibrated instruments.

Result: The results of this study the statistically significant were seen among the age of menarche and the BMI, pearson chi-square is 21.876 and $p$ value is 0.009 and also statistical significant was seen when compared regularity of periods with BMI, pearson chi-square is 10.018 and $p$ value is 0.01 . There was no statistical significant when compared waist-hip ratio with age of menarche and regularity of periods.

Conclusion: The age of menarche had a tight connection with BMI. Increase in BMI causes early age of menarche. So having increased body fat, increased body weight, high intake of protein, high-calories foods and sedentary life style causes early age of menarche in young healthy girls.

Keywords: Menarche, Metabolic syndrome, Type II diabetes mellitus

\section{Introduction}

One of the decisive stages in human growth and development process is puberty. Menarche is one of

\section{Corresponding Author:}

\section{Dr. D. Sudha}

Associate Professor, Department of Physiology, Melmaruvathur Adhiparasakthi Institute of Medical Sciences and Research, Melmaruvathur e-mail: ssudha91@yahoo.com the signs of puberty ${ }^{1}$. Menarche is defined as the first occurrence of menstruation in girls ${ }^{2}$. Menstrual cycle is a recurrent occurrence during the reproductive period in female that include changes in structural, functional and hormonal in the reproductive system. Menstruation takes place due to the actions of the hormones such as estrogen and progesterone. These hormones are regulated through the hypothalamo-pituitary activity. The release of gonadotropin releasing hormone $(\mathrm{GnRH})$ from the hypothalamus influences the release of gonadotropins (follicular stimulating hormone and luteinizing hormone) from the anterior pituitary acts on 
the uterus and the ovaries to cause menstruation. The release of GnRH can be affected by leptin. Leptin are hormones secreted in adipose tissue. Increase in rate of initiation of puberty is seen in girls having increased level of leptin which trigger the activation of $\mathrm{GnRH}^{3}$. In high BMI girls, where increased adipose cells and leptin resistance causes increase in leptin ${ }^{4}$. Menarche is affected by many factors such as genetic factors, race, environmental conditions, nutrition, physical activity, geographic location, urban or rural residence, health status, psychological factors, blindness, body mass index (BMI), family size, socioeconomic status, parental education level, occupation of parents, loss of parents, child sexual abuse, physical stress, tea consumption and passive smoking ${ }^{5}$. Among different populations the age of menarche ranges between 9 and 13 years $^{6}$. According to a study done by Gaudineau et al., stated that the climatic changes and conservative family background were closely related to the age of menarche during the early nineteenth century ${ }^{7}$. The rate of decrease in the age of menarche is 3 months for every 10 years ${ }^{8}$. Now-adays, the rate of decrease in the age of menarche shows equal proportions in developed and developing countries due to the fast changes taking place in the socioeconomic status, increased access to health case and excess intake of high calories food ${ }^{9}$. Occurrence of menarche at the earlier age has been attributed to a significant number of adverse health outcomes. Depression, eating disorders, metabolic syndrome and Type II diabetes mellitus have been identified as the major adverse health related issues. Furthermore in relation to early age of menarche has been identified as a risk factor for breast and endometrial cancer due to the increased exposure to estrogen. Hence, it is important to give awareness in adopting healthy eating habits and involving in daily physical exercise. Only few such studies have been done in India. The aim of our study is to find the influence of BMI on the age of menarche and also the duration of menstrual cycle and menses in young healthy girls.

Materials and Method: A cross-sectional study with a sample size of 200 female students between the age group of 17 - 19 years attending different courses (MBBS, BDS, AHS and BPT) in Melmaruvathur Adhiparasakthi Institute of Medical Sciences and Research, Melmaruvathur. In this study, the inclusion criteria were the healthy female students without any abnormal menstrual conditions. The exclusion criteria in this study were gynaecological disorders, anemia and history of drug intake affecting menstrual cycle and having chronic diseases. Ethical research committee approval was obtained. The study was conducted in the department of Physiology, MAPIMS. The study protocol was clearly explained to the subjects and informed written consent was obtained. Anthropometric parameters (Height in meters, Body weight in $\mathrm{Kg}$, Waist circumference in $\mathrm{cm}$ and Hip circumference in $\mathrm{cm}$ ) were measured in all the subjects. Cross - sectional data on age of menarche, duration of menstrual cycle and menses, diet, exercise and other relevant details were obtained through self-administered questionnaire.

Statistical analysis: Data are analyzed by using SPSS software. The data are also given in count and percentage and followed by pearson chi-square test. It showed statistical significant and the significance level was fixed at $\mathrm{p}<0.05$.

\section{Result}

Table 1: Comparison of mother's age of menarche with the number of girls (\%)

\begin{tabular}{|c|c|c|}
\hline Mother age at menarche (in years) & Number of mothers (\%) & Number of girls (\%) \\
\hline $10-11$ years & $2(1 \%)$ & $131(65)$ \\
\hline $12-13$ years & $46(23 \%)$ & $50(25 \%)$ \\
\hline $14-15$ years & $104(52 \%)$ & $5(2.5 \%)$ \\
\hline $16-18$ years & $48(24 \%)$ & $(\%)$ \\
\hline
\end{tabular}


Table 2: Comparison of Age of Menarche with waist-hip ratio

\begin{tabular}{|c|c|c|c|c|c|}
\hline & & & \multicolumn{2}{|c|}{ Waist-hip ratio level } & \multirow{2}{*}{ Total } \\
\hline & & & $<=0.85$ & $>0.85$ & \\
\hline \multirow{8}{*}{ Age at menarche group } & \multirow{2}{*}{ 10-11 Years } & Count & 1 & 13 & 14 \\
\hline & & $\%$ & $2.2 \%$ & $8.4 \%$ & $7.0 \%$ \\
\hline & \multirow{2}{*}{$12-13$ Years } & Count & 28 & 103 & 131 \\
\hline & & $\%$ & $60.9 \%$ & $66.9 \%$ & $65.5 \%$ \\
\hline & \multirow{2}{*}{ 14-15 Years } & Count & 15 & 35 & 50 \\
\hline & & $\%$ & $32.6 \%$ & $22.7 \%$ & $25.0 \%$ \\
\hline & \multirow{2}{*}{16 Years } & Count & 2 & 3 & 5 \\
\hline & & $\%$ & $4.3 \%$ & $1.9 \%$ & $2.5 \%$ \\
\hline \multirow[t]{2}{*}{ Total } & & Count & 46 & 154 & 200 \\
\hline & & $\%$ & $100.0 \%$ & $100.0 \%$ & $100.0 \%$ \\
\hline
\end{tabular}

Table 3: Comparison of age of menarche with BMI

\begin{tabular}{|c|c|c|c|c|c|c|c|}
\hline & & & & BMI clas & ification & & \\
\hline & & & $\begin{array}{c}<18.5 \\
\text { Underweight }\end{array}$ & $\begin{array}{c}18.5-24.99 \\
\text { Normal }\end{array}$ & $\begin{array}{c}25-29.99 \\
\text { Overweight }\end{array}$ & $\begin{array}{c}\text { Above } 30 \\
\text { Obese }\end{array}$ & Total \\
\hline & $10.11 \mathrm{~V}$. & Count & 0 & 10 & 4 & 0 & 14 \\
\hline & 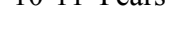 & $\%$ & $0 \%$ & $6.8 \%$ & $14.3 \%$ & $0 \%$ & $7.0 \%$ \\
\hline & & Count & 6 & 102 & 19 & 4 & 131 \\
\hline & $12-15$ 1 Cais & $\%$ & $35.3 \%$ & $69.9 \%$ & $67.9 \%$ & $44.4 \%$ & $65.5 \%$ \\
\hline 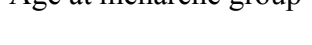 & & Count & 10 & 31 & 4 & 5 & 50 \\
\hline & 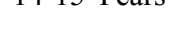 & $\%$ & $58.8 \%$ & $21.2 \%$ & $14.3 \%$ & $55.6 \%$ & $25.0 \%$ \\
\hline & 16 Yooma & Count & 1 & 3 & 1 & 0 & 5 \\
\hline & 101 adis & $\%$ & $5.9 \%$ & $2.1 \%$ & $3.6 \%$ & $0 \%$ & $2.5 \%$ \\
\hline Total & & Count & 17 & 146 & 28 & 9 & 200 \\
\hline & & $\%$ & $100.0 \%$ & $100.0 \%$ & $100.0 \%$ & $100.0 \%$ & $100.0 \%$ \\
\hline
\end{tabular}

Table 4: Comparison of regularity of periods with BMI

\begin{tabular}{|c|c|c|c|c|c|c|c|}
\hline & \multicolumn{4}{|c|}{ BMI classification } & \multirow[b]{2}{*}{ Total } \\
\hline & & & $\begin{array}{c}\quad<18.5 \\
\text { Underweight }\end{array}$ & $\begin{array}{c}18.5-24.99 \\
\text { Normal }\end{array}$ & $\begin{array}{c}25-29.99 \\
\text { Overweight }\end{array}$ & $\begin{array}{l}\text { Above } 30 \\
\text { Obese }\end{array}$ & \\
\hline \multirow{4}{*}{ Regular Irregular } & \multirow{2}{*}{1.00} & Count & 17 & 131 & 20 & 8 & 176 \\
\hline & & $\%$ & $100.0 \%$ & $89.7 \%$ & $71.4 \%$ & $88.9 \%$ & $88.0 \%$ \\
\hline & \multirow{2}{*}{2.00} & Count & 0 & 15 & 8 & 1 & 24 \\
\hline & & $\%$ & $.0 \%$ & $10.3 \%$ & $28.6 \%$ & $11.1 \%$ & $12.0 \%$ \\
\hline \multirow[t]{2}{*}{ Total } & & Count & 17 & 146 & 28 & 9 & 200 \\
\hline & & $\%$ & $100.0 \%$ & $100.0 \%$ & $100.0 \%$ & $100.0 \%$ & $100.0 \%$ \\
\hline
\end{tabular}




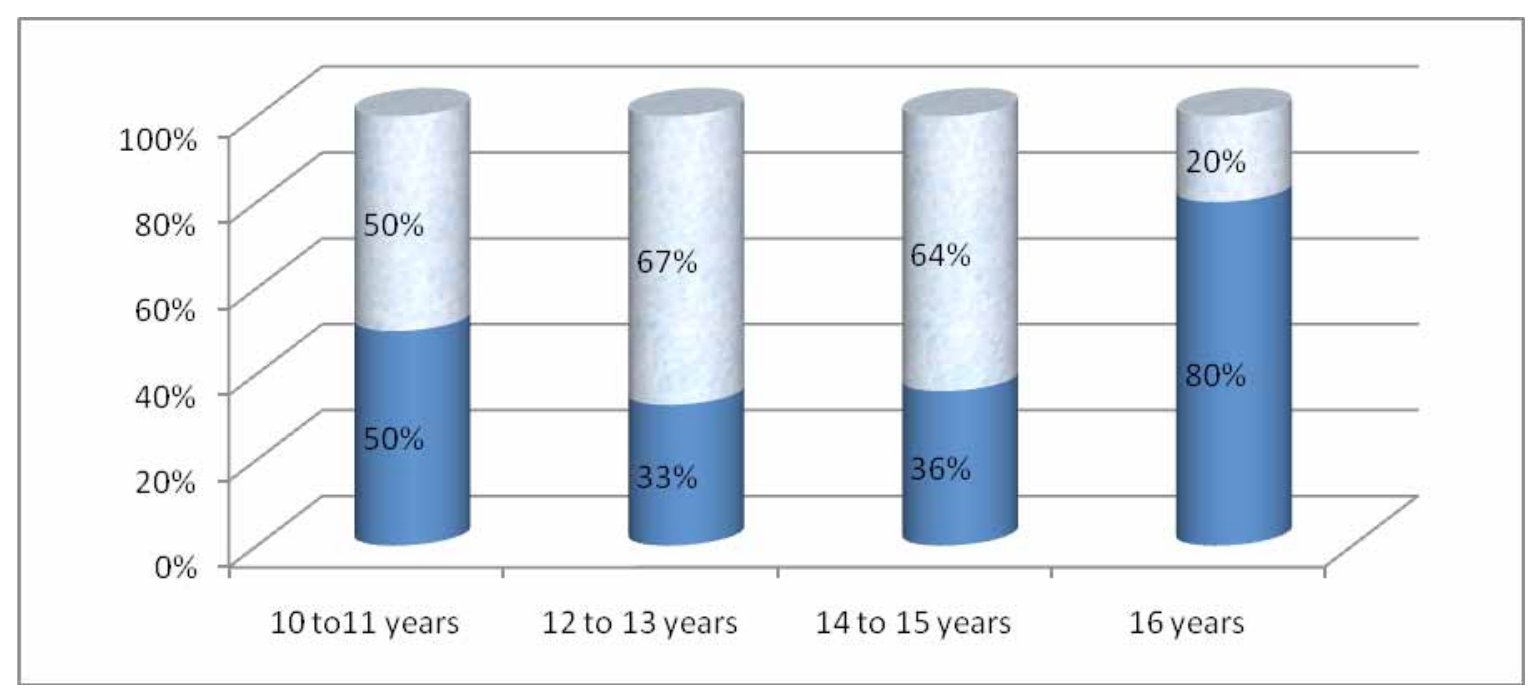

Figure 1: Comparison of age of menarche with exercise.

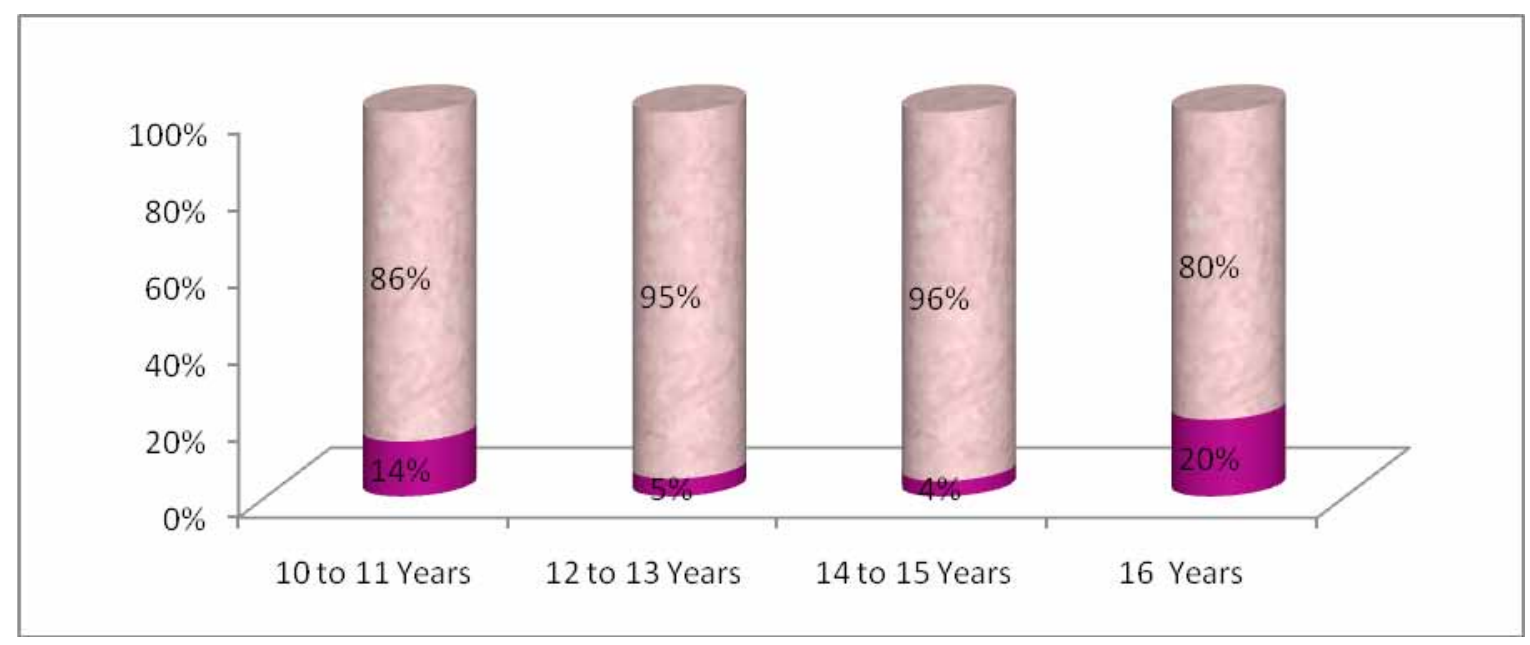

Figure 2: Comparison of age of menarche with vegetarian and non-vegetarian diet.

\section{Discussion}

In this study 200 healthy girls of MAPIMS from different courses (MBBS, BDS, BPT and AHS) were involved with age of menarche varying from 10 years to 16 years. The mean age of menarche among the girls was higher in 12-13 years group with $131(65.5 \%)$. The mean age of menarche of mothers was highly significant at the 14-15 years with $104(52 \%)$ than the daughters age of menarche was 12 - 13 years with $131(65.5 \%)$ which are given in table 1 . In table 2 , the comparison of age of menarche with waist-hip ratio showed a higher percentage of girls with $103(66.9 \%)$ at the age of $12-13$ years of menarche and also when compared with BMI and the age of menarche as in table 3 also showed that high BMI values are seen in girls with age of menarche at
$12-13$ years menarche group, the pearson chi-square is 21.876 and $p$ value is 0.009 . The girls had regular periods even with high waist-hip ratio which was statistically not significant but in table 4it was statistically significant that high BMI had irregular periods when the regularity of periods is compared with BMI, pearson chi-square is 10.018 and $p$ value is 0.01 . The figure 1 compares the exercising and non-exercising girls with the age of menarche, which showed that non-exercising girls are higher in $12-13$ years of age of menarche group. When comparing vegetarian and non-vegetarian group of girls compared with the age of menarche showed higher group of girls are seen at the age of menarche at $12-13$ years and $14-15$ years as shown in Figure 2. 
The age of menarche is important evidence in the phase of maturationin sexual life in girls. In this study, the age of menarche in young healthy girls is $12-13$ years when compared with the age of menarche of the mothers $14-15$ years. This statement is supported by thestudy done by Tsuzaki et al., stated that there is a trend of decrease in the years of age of menarche among the girls ${ }^{10}$. A study done by Kusum S Mane et al., had a positive correlation between menarcheal age of mother and their daughters ${ }^{11}$. One of thestudy done by Guillette et al. and many other studies proved that mothers age of menarche have greater influence in genetic factors on the age of menarche of their daughters ${ }^{12}$. Many studies proved that there is an inverse correlation between the age of menarche and BMI. Increase in weight (overweight and obesity) causes gradual decrease in the age of menarche ${ }^{13}$. Girls having high BMI tend to get menarche at the earlier years than those with normal weight ${ }^{14}$. Pejhan A done a study to create the relationship between the age of menarche and anthropometric indices in girls and he found that the girls having higher the BMI had lower the age of menarche ${ }^{15}$. Wronka et al., reported in his study that age of menarche and BMI are inversely correlated and he also compared with the socioeconomic status of the participants ${ }^{16}$. A study done of Filer BR found that the irregular cycle is seen in girls having high body fat and obesity ${ }^{17}$. The subjects having High BMI with sedentary life style without any exercise habits may have an effect on the level and equilibrium of endogenous hormones which are required for normal menstrual functions. In Dars S et al. in their study, the results showed that non-exercising girls had irregular periods ${ }^{18}$.Moisan J et al., done a study on physical activity and the age of menarche proved that physical activities had a greater role in the age of menarche ${ }^{19}$. There was a strong relationship between the hormonal factors such as Insulin and sex hormones binding globulin (SHBG) have an effect obesity and irregular periods ${ }^{20}$.

Conclusion: Our study concludes that the mean age of menarche was gradually decreasing from $13-14$ years to $12-13$ years and lowest age of menarche at $10-11$ years. The mother's age of menarche with their daughters was statistically significant. The statistical significant is also seen when compared the age of menarche with anthropometric parameters and also showed variation in waist-hip ratio. It is found that irregular periods were present in overweight and obsess girls. When age of menarche and physical exercise were compared it showed statistical significant. The non-vegetarian girls had early age of menarche when compared with vegetarian girls. Having high BMI, sedentary life style with increase in the subcutaneous fat influences the hormonal changes which are the possible causes to get early age of menarche in girls. More such studies should be done with increased population group and adding the Bio-social factors.

Interest of Conflict: No conflict

\section{Source of Funding: Self}

\section{References}

1. Gardner DG, Shoback DM, Greenspan FS. Greenspan's basic and clinical endocrinology. San Fransisco: McGraw-Hill Medical; 2007.

2. Akter S, Jesmin S, Islam M, Sultana SN, Okazaki O, Hiroe M, et al. Association of age at menarche with metabolic syndrome and its components in rural Bangladeshi women. NutrMetabol 2012;9(99):1-7.

3. Mc Dowell MA, Brody DJ, Hughes JP. Has age at menarche changed? Results from the National Health and Nutrition Examination Survey (NHANES) 1999-2004. J Adolesc Health. 2007;40(3):227-31.

4. Apter D. The role of leptin in female adolescence. Annal NY Acad Sci. 2003;997(1):64-76.

5. Tehrani F R, Mirmiran P, Gholami R, Moslehi N, Azizi F. Int J EndocrinolMetab. Factors Influencing Menarcheal Age: Results from the Cohort of Tehran Lipid and Glucose Study. 2014;12(3):e16130.

6. Chumlea WC, Schubert CM, Roche AF, Kulin HE, Lee PA, Himes JH,et al. Age at menarche and racial comparisons in US girls. Pediatrics. 2003;111(1):110-3.

7. Gaudineau A, Ehlinger V, Vayssiere C, Jouret B, Aenaud C, Godeau E. Factors associated with early menarche: results from the French Health Behaviour in School-aged Children (HBSC) study. BMC Public Health 2010;10:175.

8. Tanner JM. Fetus into Man. UK: Castlemead Publications, 1989.

9. Adadevoh SW, Agble TK, Hobbs C, Elkins TE. Menarcheal age in Ghanaian school girls. Int J GynaecolObatet 1989;30(1):63-8.

10. Tsuzaki S, Matsuo $\mathrm{N}$, Ogata $\mathrm{T}$, Osano $\mathrm{M}$. Lack of linkage between height and weight and age at menarche during the secular shift in 
growth of Japanese children. Ann Hum Biol 1989;16(5):429-36.

11. Kusum S Mane, Holyachi Sharankumar, Badesab Bheemayya. Age At Menarche And Factors Associated Among Girls Of A Primary Health Centre Area In Davangere, India. National Journal of Community Medicine 2016; 7(5):417-420.

12. Guillette LJ Jr, Gross TS, Masson GR, Matter JM, Percival HF, Woodward AR. Developmental abnormalities of the gonad and abnormal sex hormone concentrations in juvenile alligators from contaminated and control lakes in Florida. Environ Health Perspect 1994;102(8):680-8.

13. AL-Awadhi N. Age at menarche and its relationship to body mass index among adolescent girls in Kuwait. BMC Public Health 2013; 13: 29.

14. Ahmed LM, Ong KK, Dunger BD. Childhood obesity and the timing of puberty. Trends in Endocrinol and Metab 2009; 20(5):237-42.

15. Pejhan A, Moghaddam HY, Najjar L, Akaberi
A. The relationship between menarche age and anthropometric indices of girls in Sabzevar, Iran.J Pak Med Assoc.2013;63(1):81-84.

16. Wronka. Association between BMI and age at menarche in girls from different socio economic groups. Anthropol Anz.2010; 68(1):43-52.

17. Filer BR. Obesity and reproduction. JLGH 2009; 4(4):134-135.

18. Dars S, Sayed K, Yousufzai Z. Relationship of menstrual irregularities to BMI and nutritional status in adolescent girls. Pak J Med Sci 2014; 30(1):140-144.

19. Moisan J, Meyer F, Gingras S. Leisure physical activity and age at menarche. Med Sci Sports Exerc 1991;23(10):1170-5.

20. Hahn AK, Wise AL, Riis HA, Mikkelsen ME, Rothman JK, Banholzer K, et al. Correlates of menstrual cycle characteristics among nulliparous Danish women. Clinical Epidemiology 2013; 5:311-319. 